\begin{tabular}{|l|l|l||}
\hline \multicolumn{2}{|c|}{ PublisherInfo } \\
\hline \hline PublisherName & $:$ & BioMed Central \\
\hline \hline PublisherLocation & $:$ & London \\
\hline \hline PublisherImprintName & $:$ & BioMed Central \\
\hline \hline
\end{tabular}

\title{
Oxidant lung injury in cystic fibrosis
}

\begin{tabular}{|l|l|l||}
\hline \multicolumn{2}{|c||}{ ArticleInfo } \\
\hline \hline ArticleID & $:$ & 1631 \\
\hline \hline ArticleDOI & $:$ & $10.1186 /$ rr-2001-68563 \\
\hline \hline ArticleCitationID & $:$ & 68563 \\
\hline \hline ArticleSequenceNumber & $:$ & 42 \\
\hline \hline ArticleCategory & $:$ & Paper Report \\
\hline \hline ArticleFirstPage & $:$ & 1 \\
\hline \hline ArticleLastPage & $:$ & 4 \\
\hline \hline & & RegistrationDate $: 2001-9-19$ \\
& $:$ & Received \\
ArticleHistory & Accepted 2000-11-23 & $:$ 2001-9-19 \\
& $:$ & OnlineDate $\quad: 2001-9-19$ \\
\hline \hline ArticleCopyright & $:$ & Biomed Central Ltd2001 \\
\hline \hline ArticleGrants & $:$ & \\
\hline \hline ArticleContext & $:$ & 129312211 \\
\hline \hline
\end{tabular}


James Chmiel, Aff1

Corresponding Affiliation: Aff1

Affl Case Western Reserve University School of Medicine, Cleveland, OH, USA

\section{Keywords}

Cystic fibrosis, eicosanoids, isoprostanes, oxidants, peroxidation, prostaglandins, vitamin E

\section{Context}

In cystic fibrosis (CF) lung disease, the inflammatory response has been shown to be excessive relative to the burden of infection. The inflammatory response is characterized by a predominately neutrophilic infiltrate. The neutrophils release mediators that damage tissues, result in deleterious functional alterations, and interfere with host defenses. Many of the inflammatory mediators result in oxidant lung injury. It is well known that CF lung disease is associated with enhanced lipid peroxidation. New $\mathrm{F}_{2}$-isoprostanes have been described that are formed from the nonenzymatic peroxidation of arachidonic acid on membrane phospholipids. The $\mathrm{F}_{2}$-isoprostanes may provide markers of oxidative stress in vivo. The aims of this study were to determine whether $\mathrm{F}_{2}$-isoprostanes are (a) altered at baseline in $\mathrm{CF}$, (b) affected by vitamin $\mathrm{E}$, and (c) correlate with either lung function or thromboxane metabolite excretion.

\section{Significant findings}

Concentrations of urinary 8-iso-PGF $2 \mathrm{a}$, an index of lipid peroxidation, and 11-dehydro-TXB 2 , a marker of platelet activation, were significantly greater in CF patients than in healthy subjects. Urinary excretion of 8-iso-PGF $2 \mathrm{a}$ was inversely related to forced expiratory volume in $1 \mathrm{~s}$. Inhibition of COX-1 and/or COX-2 significantly decreased excretion of 11-dehydro- $\mathrm{TXB}_{2}$ but not 8-iso-PGF $2 \mathrm{a}$. $\mathrm{CF}_{\text {patients }}$ who tripled their dose of vitamin $\mathrm{E}$ had decreased urinary excretion of 8-iso-PGF 2 a and 11-dehydro$\mathrm{TXB}_{2}$. The authors conclude that since the urinary excretion of 8-iso-PGF $2 \mathrm{a}$ is elevated and correlated with lung function in $\mathrm{CF}$, then enhanced lipid peroxidation may play a role in disease progression. As 11-dehydro-TXB2 but not 8-iso-PGF2a excretion decreased with administration of COX inhibitors, enhanced lipid peroxidation by F2-isoprostanes is not due to persistent platelet activation, but rather may 
be due to a pro- and anti-oxidant imbalance in the CF lung. The authors also conclude that further studies of increased doses of vitamin $\mathrm{E}$ in $\mathrm{CF}$ are warranted.

\section{Comments}

This study provides support for observations that there is an imbalance between pro- and anti-oxidants in the excessive inflammatory response of the CF lung. The study would have been strengthened had the inclusion criteria included pancreatic insufficiency and the exclusion criteria included pancreatic sufficiency and administration of specific medications including systemic steroids, systemic antibiotics (especially nephrotoxic antibiotics), and oxygen therapy. The authors note, 'neither specific drugs (eg antibiotics) nor home oxygen $(n=6)$ accounted for enhanced $\mathrm{F}_{2}$-isoprostane formation'. However, the number of subjects is probably too small to perform an adequate subgroup analysis. Since the authors hypothesize that enhanced lipid peroxidation may, in part, be due to inadequate vitamin $\mathrm{E}$ supplementation, they should have determined if there was any association between urinary excretion of 8-iso-PGF $2 \mathrm{a}$ and baseline serum vitamin E levels. Nonetheless, urinary 8-iso-PGF $2 \mathrm{a}$ excretion has potential as a non-invasive biochemical marker in studies of anti-oxidants in $\mathrm{CF}$. In addition to the future studies of vitamin E outlined by the authors, they should consider determining if the formation of $\mathrm{F}_{2}$-isoprostanes correlates with other markers of inflammation (lung neutrophils and interleukin-8) or whether lipid peroxidation is increased during pulmonary exacerbations with a return towards baseline upon completion of treatment.

\section{Methods}

RIA, gas chromotography/mass spectrometry, high-performance liquid chromotography

\section{Additional information}




\section{References}

1. Ciabattoni G, Davi G, Collura M, Iapichino L, Pardo F, Ganci A, Romagnoli R, Maclouf J, Patrono C: In vivolipid peroxidation and platelet activation in cystic fibrosis. Am J Respir Crit Care Med. 2000, 162: 1195-1201.

This PDF file was created after publication. 